\title{
Epoxidation of Propylene by Hydrogen Peroxide Catalyzed by the Silanol-Functionalized Polyoxometalates-Supported Ferrate: Electronic Structure, Bonding Feature, and Reaction Mechanism
}

\author{
Yun-Jie Chu ${ }^{1}$, Gang $\mathrm{Sun}^{2}$, Xue-Mei Chen ${ }^{1}$, and Chun-Guang Liu ${ }^{2}$ \\ ${ }^{1}$ Northeast Electric Power University \\ ${ }^{2}$ Beihua University
}

June 19, 2020

\begin{abstract}
Hydrogen peroxide (H2O2), as clean oxidant, has long suffered from low efficiency and selectivity for the oxidation of olefins. In the present paper, the redox important ferrate anion (FeO42-) has been anchored into a silanol-decorated polyoxometalates (POM) to form single-site supported Fe-POM catalyst. And possible reaction mechanism for the epoxidation of propylene with hydrogen peroxide ( $\mathrm{H} 2 \mathrm{O} 2$ ) catalyzed by the Fe-POM catalyst have been investigated based on density functional theory with M06L functional. The study of molecular geometry, electronic structure, and bonding feature shows that the Fe-POM complex can be viewed as a high-valent $\mathrm{Fe}$-oxo $(\mathrm{Fe}=\mathrm{O})$ species. The propylene molecule was activated by the Fe-POM catalyst via an effective electron transfer from propylene to the Fe-POM catalyst to form a cation propylene radical. Due to the high reactivity of radical species, the calculated activation energy barrier is only $4.50 \mathrm{kcal}$ mol- 1 for epoxidation of propylene to epoxypropane catalyzed by the Fe-POM catalyst. Subsequently, the calculated free energy profiles show that H2O2 was decomposed into a $\mathrm{H} 2 \mathrm{O}$ molecule and a surface $\mathrm{O}$ species over the Fe-POM catalyst, and the remaining $\mathrm{O}$ atom attaches to the exposed the Fe center, resulting in the replenishing of Fe-POM catalyst via a two-state reaction pathway. The calculated activation energy barrier for this process is $23.42 \mathrm{kcal} \mathrm{mol-1}$, and thus decomposition of $\mathrm{H} 2 \mathrm{O} 2$ is the rate-determining step for the whole reaction. The Fe center serves as an electron acceptor, accepting electrons from the binding propylene molecule to form radical species in the first half of the reaction, and acts as the role of electron donor in the rest reaction steps to eliminate the radical feature, reduce the reactivity, and stop the reaction at the stage of the desired epoxypropane product.
\end{abstract}

\section{Hosted file}

EP-PAPER-CR1.doc available at https://authorea.com/users/334981/articles/460922epoxidation-of-propylene-by-hydrogen-peroxide-catalyzed-by-the-silanol-functionalizedpolyoxometalates-supported-ferrate-electronic-structure-bonding-feature-and-reactionmechanism 